\title{
Aedes aegypti eggs oviposited on water surface collected from field ovitraps in Nova Iguaçu City, Brazil
}

\author{
Eduardo Dias Wermelinger ${ }^{[1]}$, Aldo Pacheco Ferreira ${ }^{[2]}$, \\ Raimundo Wilson de Carvalho ${ }^{[1],[3],}$ Adriano Anselmo da Silva ${ }^{[4]}$ \\ and Ciro Villanova Benigno ${ }^{[1]}$
}

[1]. Departamento de Ciências Biológicas, Escola Nacional de Saúde Pública Sérgio Arouca, Fundação Oswaldo Cruz, Rio de Janeiro, Brasil. [2]. Centro de Estudo da Saúde do Trabalhador e Ecologia Humana, Escola Nacional de Saúde Pública Sérgio Arouca, Fundação Oswaldo Cruz, Rio de Janeiro, Brasil. [3]. Universidade Iguaçú, Nova Iguaçú, Rio de Janeiro, Brasil. [4]. Secretaria Municipal de Saúde de Nova Iguaçú, Prefeitura Municipal de Nova Iguaçú, Nova Iguaçu, Rio de Janeiro, Brasil.

\begin{abstract}
Introduction: Aedes aegypti eggs can be collected from the water surface. Methods: Aedes aegypti oviposition from 97 field ovitraps was studied. Results: Of the 16,016 eggs collected, 11,439 were obtained from paddles in ovitraps and 4,577 from water. Further, $89(91.8 \%)$ traps contained eggs on water and $22(22.7 \%)$ traps contained eggs only on water. Conclusions: In field traps, Aedes aegypti females usually oviposit some eggs on water surface suggesting that they might also oviposit on water of some natural breeding, and this possibility needs to be investigated. Eggs oviposited on water need to be considered for collecting trap data.
\end{abstract}

Keywords: Aedes aegypti. Trap. Water oviposition.

At present, in Brazil, Aedes aegypti is the mosquito vector for dengue, Chikungunya and, more recently, Zika virus. Thus, while there is no vaccine for these viruses, the A. aegypti control has remained a challenge for Brazilian public health services. In particular, the entomological surveillance represents a fundamental procedure for guiding the control actions. In the Brazilian National Program of Dengue Control, the Breteau and House index have been the most used parameter for entomological surveillance services ${ }^{(1)}$. These indexes are calculated based on the larvae and pupae collected in the inspected natural breeding sites and, hence, they do not consider the excessive breeding events, which usually are not found in the field, such as water tanks inside houses not accessed by the vector control services ${ }^{(2)(3)}$. To face this problem, oviposition traps are a valuable tool because they might estimate the infestation rate without requiring the inspection of urban water containers and breeding sites. The ovipositon traps used for A. aegypti surveillance are usually simple, economical, and easy to manipulate and to build because, in general, they involve a small recipient with water and a hardboard paddle where the females oviposit their eggs. Therefore, the infestation can be measured depending on the number of eggs on the paddles ${ }^{(4)}$.

Corresponding author: Dr. Eduardo Dias Wermelinger. Depto. Ciências Biológicas/Escola Nacional de Saúde Pública Sérgio Arouca/FIOCRUZ. Rua Leopoldo Bulhões 1480, Manguinhos, 21045-900 Rio de Janeiro, Brasil. Phone: 5521 2208-2061; Mobile: 5521 9-9441-8071

e-mail: edw@fiocruz.br

Received 17 March 2015

Accepted 9 June 2015
However, some studies have shown the Aedes aegypti eggs are deposited on the water surface and not only on the rough wet surfaces, and these eggs on water are not accounted in surveillance traps and, surprisingly, they are not even considered in studies about oviposition behavior. However, most observations of eggs on water surface were conducted in laboratories ${ }^{(5)(6)(7)(8)(9)(10)(11)(12)(13)}$, and few field observations were only accomplished by Chadee et al. ${ }^{(14)}$ in Trinidad and, more recently, by Soares et al. ${ }^{(15)}$ in a small town in Brazil (30,716 inhabitants) within a semiarid area. All the studies accomplished in Brazil ${ }^{(12)(13)(15)}$, suggest the relevance of the eggs deposited on water surface for controlling actions. Soares et al. ${ }^{(15)}$ found $11.2 \%$ of all eggs in the water in $96 \%$ of the field traps and reported significant increase in the number of eggs in the water when the relative humidity dropped below $40 \%$. In the laboratory, Madeira et al. ${ }^{(12)}$ also showed that, at lower humidity, females oviposited more eggs on the liquid surface. Gomes et al. ${ }^{(13)}$ conducted a laboratory experiment and indicated that eggs oviposited on water surface showed faster eclosion and argued that this particularity in the environment could lead to faster colonization. These data suggest the necessity for considering these eggs that are oviposited on the water in Brazilian urban environment, especially in big cities and under epidemiological realistic weather conditions for further analyses and discussions to improve the understanding of their epidemiological and surveillance relevance. Therefore, this study performed descriptive statistics of $A$. aegypti eggs oviposited on water surface in field ovitraps in a large urban area during the hot period and determined the possible relevance of this behavior. 
Traps were set during the hot period from October 2009 to March 2010 in Nova Iguaçu City (796,257 inhabitants in 2010 according to http://www.cidades.ibge.gov.br); this city belongs to a very large urban region of the State of Rio de Janeiro. Ovitrap included a round black plastic vase (height, $12 \mathrm{~cm}$; top diameter, $13.5 \mathrm{~cm}$; bottom diameter, $2.5 \mathrm{~cm}$ ) filled with deionized tap water; the vase contained wooden paddles with a rough surface $(14 \times 2.5 \mathrm{~cm})$ fixed vertically inside the vase. In all, 237 ovitraps were placed outside houses in the chosen area for a period of one week. At the end of the week, the ovitraps were transported to the laboratory for egg counting. The eggs from the tap water were collected by removing the paddles; the water was filtered through a piece of white tissue thin enough to retain the eggs and then these tissues were protected in small, individual tubes. In the laboratory the eggs in the paddles and those retained in the tissues were counted under a stereomicroscope. After counting, each paddle and tissue were placed in trays containing tap water for hatching and then L3 larvae samples were morphologically identified using the stereomicroscope. At least 3 larvae per tray were identified. The negative traps (without eggs) and the empty ones (without water) were discarded. Any interference from interspecific competition was avoided by considering only those traps that contained A. aegypti eggs. Thus, all traps that contained at least one larva identified as being different from $A$. aegypti were excluded. Thus, 97 trap samples were used for analysis.

Descriptive statistics was used to analyze the data for eggs obtained from paddles and water (mean, \pm standard deviation, coefficient of variation, frequency). The normality tests ShapiroWilk, Lilliefors, and Kolmogorov-Smirnov were performed using OriginLab 9.0 statistics software.

Of the 97 traps used for observations, 89 (91.8\%) had eggs on the water surface. From all traps, 16,016 eggs were obtained $(\mathrm{m}=165.11 \pm 175.18, \mathrm{cv}=106.10 \%)$; of these, 11,439 (71.4\%) eggs were oviposited on paddles; $(\mathrm{m}=117.93 \pm 156.26$, $\mathrm{cv}=132.50 \%)$ and 4,577 on water surface $(28.6 \%)(\mathrm{m}=47.19 \pm$ 43.74, cv=92.69\%). The frequency data are shown in Table 1. Eight (8.2\%) traps had eggs only on paddles whereas $22(22.7 \%)$ traps contained eggs only on water surface. The egg data from paddles and from water surface were not normally distributed.

The percentage of eggs oviposited on paddles and on water surface was consistent with the field observation of Chadee et al. ${ }^{(14)}$ and Soares et al. ${ }^{(15)}$ who showed that female $A$. aegypti would rather oviposit on paddles than on water surface. The high percentage of traps with eggs on water surface (91.8\%) was also reported by Soares et al ${ }^{(15)}(96 \%)$ strongly suggesting that there is an A. aegypti behavior pattern to oviposit some eggs on the water surface as well.

It is relevant to observe the expressive percentage (22.7\%) of traps with eggs only on water surface, which would have been interpreted as a negative result if only the data from paddles would have been considered. We suspect that this paddle rejection might be due to the presence of kairomone left by predators or natural enemies such as ants or cockroaches, or the eggs might have been attacked by these predators while they were on the paddles. Madeira et al. ${ }^{(12)}$ witnessed this incidence in
TABLE 1 - Frequency of eggs of Aedes aegypti on the water surface in field traps.

\begin{tabular}{|c|c|c|}
\hline Classes & Traps & Percentage \\
\hline $0-10$ & 25 & 25.8 \\
\hline $10-20$ & 1 & 1.0 \\
\hline $20-30$ & 14 & 14.4 \\
\hline $30-40$ & 7 & 7.2 \\
\hline $40-50$ & 9 & 9.3 \\
\hline $50-60$ & 12 & 12.4 \\
\hline $60-70$ & 7 & 7.2 \\
\hline $70-80$ & 5 & 5.2 \\
\hline $80-90$ & 4 & 4.1 \\
\hline $90-100$ & 4 & 4.1 \\
\hline $100-110$ & 2 & 2.1 \\
\hline $110-120$ & 0 & 0.0 \\
\hline $120-130$ & 0 & 0.0 \\
\hline $130-140$ & 2 & 2.1 \\
\hline $140-150$ & 2 & 2.1 \\
\hline $150-160$ & 1 & 1.0 \\
\hline $160-170$ & 0 & 0.0 \\
\hline $170-180$ & 1 & 1.0 \\
\hline $180-190$ & 0 & 0.0 \\
\hline $190-200$ & 0 & 0.0 \\
\hline $200-210$ & 0 & 0.0 \\
\hline $210-220$ & 0 & 0.0 \\
\hline $220-230$ & 0 & 0.0 \\
\hline $230-240$ & 1 & 1.0 \\
\hline Total & 97 & 100.0 \\
\hline
\end{tabular}

the field, and this event might likely be quite common in nature. Soares et al. ${ }^{(15)}$ also found eggs only in the water, but at a lower percentage ( 23 of 500 surveys $=4.6 \%$ ). Was this percentage difference due to a possible lower presence of predators in the semiarid environment? Our results show that the percentage of total eggs on water $(28.2 \%)$ was more than twice as that reported by Chadee et al..$^{(14)}(12.6 \%)$ and Soares et al. ${ }^{(15)}$ (11.2\%), which indicates the need for more field investigations.

These field observations suggest that eggs oviposited on the water surface should be considered during entomological surveillance, especially during the dry periods as pointed by Chadee et al. ${ }^{(14)}$ and Soares et al. ${ }^{(15)}$. These findings also suggest that $A$. aegypti females can often oviposit some of their eggs on the water surface on, at least, some natural breeding. This possibility needs to be investigated for guiding not only the professionals of vector control but also the population on the 
discharge of breeding water. If females can oviposit some of its eggs on the water surface of breeding places, this water, even without larvae, should not be discharged into the sanitation system or in open dry grounds or pavements. This is because, in the open dry places, the eggs may withstand desiccation and be carried to breeding grounds, especially the underground ones such as drainpipes, ditches, wells, cisterns, septic tanks, and catch basins via rainwater. Many of these underground places are usually difficult to be reached by vector control services.

\section{CONFLICT OF INTEREST}

The authors declare that there is no conflict of interest.

\section{REFERENCES}

1. Ministério da Saúde. Secretaria de Vigilância em Saúde. Departamento de Vigilância Epidemiológica. Diretrizes Nacionais para a prevenção e controle de epidemias de dengue - Séria A. Normas e Manuais Técnicos. Brasília: Ministério da Saúde; 2009.

2. Wermelinger ED, Cohen SC, Thaumaturgo C, Silva AA, Ramos FAF, Souza MB, et al. Avaliação do acesso aos criadouros do Aedes aegypti por agentes de saúde do programa saúde da família no municipio do Rio de Janeiro. Rev Baiana Saude Publica 2008; 32:151-158.

3. Holcman MM, Barbosa GL, Andrade VR, Domingos MF, Gomes AHA, Silva M, et al. Infestação por Aedes aegypti em imóveis fechados nas visitas para vigilância e controle vetorial de dengue em municípios do Estado de São Paulo. Bol Epidemiol Paul (on

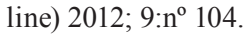

4. Gomes AC. Medidas dos níveis de infestação urbana para Aedes (Stegomyia) aegypti e Aedes (Stegomyia) albopictus em programas de vigilância entomológica. Inf Epidemiol SUS 1998; 7:49-57.
5. Association of Schools of Public Health (ASPH). Observations on the live cicle of Stegomyia calopus. Public Health Rep 1907; 22:381-383. (Cited 2015 Mar 02) Available at: https://archive.org/ details/jstor-4558880

6. Young CJ. Notes on the Bionomics of Stegomyia calopus, Meigen in Brazil. Ann Trop Med Parasitol 1922; 16:389-406.

7. O'Gower AK. The influence of the surface on oviposition by Aedes aegypti (Linn) (Diptera: Culicidae). Proc Linn Soc NSW 1957; 82:240-244.

8. Wood RJ. Oviposition in DDT-resistant and susceptible strains of Aedes aegypti (L.): eggs-laying on open-water surfaces. Bull Entomol Res 1963; 53:785-790.

9. O'Gower AK. Environmental stimuli and the oviposition behavior of Aedes aegypti var. queenslandis Theobald (Diptera, Culicidae). Anim Behav 1963; 11:189-197.

10. Goma LKH. Laboratory observations on the oviposition habits of Aedes (Stegomyia) aegypti (Linnaeus). Ann Trop Med Parasitol 1964; 58:347-349.

11. Tirapatsakun L, Tauthong P, Phanthumachinda B. Surface preferences for oviposition of Aedes aegypti in Thailand. Southeast Asian J Trop Med Public Health 1981; 12:209-212.

12. Madeira NG, Macharelli CA, Carvalho LR. Variation of the oviposition preferences of Aedes aegypti in function of substratum and humidity. Mem Inst Oswaldo Cruz 2002; 97:415-420.

13. Gomes AS, Sciavico CJS, Eiras AE. Periodicidade de oviposição de fêmeas de Aedes aegypti (Linnaeus, 1762) (Diptera: Culicidae) em laboratório e campo. Rev Soc Bras Med Trop 2006; 39:327-332.

14. Chadee DD, Corbet PS, Talbot H. Proportions of eggs laid by Aedes aegypti on different substrates within an ovitrap in Trinidad, West Indies. Med Vet Entomol 1995; 9:66-70.

15. Soares FA, Silva JC, Oliveira JBBS, Abreu FVS. Study of oviposition behavior of Aedes aegypti in two neighborhoods under the influence of semi-arid climate in the municipality of Salinas, State of Minas Gerais, Brazil. Rev Patol Trop 2015; 44:77-88. 